\title{
Las Artes Marciales Mixtas (MMA): deporte, espectáculo y economía
}

\author{
Juliana Aparecida de Oliveira CAMILO* (D) \& Mary Jane Paris SPINK (D) \\ Pontifícia Universidade Católica de São Paulo - PUCSP (Brasil) \\ Recepción: 18/11/2017; Aceptación: 10/02/2018; Publicación: 13/02/2018.
}

ORIGINAL PAPER

\section{Resumen}

El objetivo de esta investigación ha sido comprender con mayor detalle lo que son las Artes Marciales Mixtas (MMA). Para ello se realizó una investigación etnográfica durante el año 2014 en dos gimnasios de MMA, en São Paulo - Brasil. Tras convivir con deportistas y otros actores fue posible comprender mejor algunas modalidades de MMA a través de observaciones y conversaciones sobre sus prácticas. Esta investigación ha seguido la teoría Actor-Red (TAR), en diálogo con la Psicología Social Construccionista. Entre los resultados se ha identificado que el MMA es un deporte, un espectáculo y un evento en la lógica mercantilista. Además, ha sido posible comprender que el MMA es una modalidad múltiple y que no es posible interpretarla desde una versión única, estable o predefinida, ya que cada práctica que se desarrolla puede derivar en otras versiones distintas.

Palabras clave: Psicología del deporte; etnografía; artes marciales; deportes de combate; lucha; MMA.

\section{As Artes Marciais Mistas (MMA): esporte, espetáculo e economia}

\section{Resumo}

O objetivo dessa pesquisa foi compreender o que são as Artes Marciais Mistas (MMA), nos espaços onde se desenvolve suas atividades. Para isso, fizemos uma etnografia no ano de 2014 em duas academias de MMA, na cidade de São Paulo - Brasil. Foi possível entender algumas versões de MMA por meio da descrição das observações, conversações e das práticas das quais foi possível conviver com os atletas e demais pessoas. Para apoiar esta investigação, adotamos a teoria ator-rede (TAR), em diálogo com a Psicologia Social Construcionista. Esta pesquisa identificou que o MMA é um esporte, é um espetáculo e é um evento na lógica econômica. Através deste estudo compreendemos que o MMA é uma modalidade múltipla e que não é possível atribuir a ele uma versão única, estável ou predefinida, já que a cada prática no qual a modalidade está inserida, pode se derivar outras distintas versões.

Palavras-chave: Psicologia do esporte; etnografia; artes marciais; desportos de combate; luta; MMA.

\section{Mixed Martial Arts (MMA): sport, spectacle and economics}

\section{Abstract}

The aim of this research was to identify versions of Mixed Martial Arts (MMA) as practiced in different settings. For this purpose, an ethnographic study was carried out in two MMA academies in the city of São Paulo, Brazil, during 2014. It was possible to identify these different versions through observations and conversations carried out during practices in these two settings. The research was based on theoretical approaches of Actor-Network Theory in dialogue with Constructionist Social Psychology. The results suggest that MMA is concomitantly a sport, a spectacle and an event within the logic of Economics. As such, it is multiple and cannot be reduced to a single, stable, predefined version given that each modality of practice can be translated into other distinct versions.

Keywords: Sport psychology; ethnography; martial arts; combat sports; fight; MMA.

\section{Sobre la historia del MMA}

¿Cuál es ese deporte que tanto crece por el mundo y apasiona a tantas personas? En este artículo se pretende, desde esta inquietud y con esta mirada, estudiar qué son las Artes Marciales Mixtas (MMA) a través de una investigación etnográfica. La intención es contribuir a la reconstrucción o redimensionamiento de esta modalidad. Con ello se plantea facilitar herramientas para mejorar la comprensión y establecer algunas vías de entendimiento ayudando a los psicólogos y a los entrenadores a que interactúen con los luchadores. La necesidad de (re)creación, entendimiento, relativización y descripción es tarea imprescindible, y éticamente urgente, en este deporte.

El MMA se caracteriza por una lucha que emplea técnicas corporales de varias artes marciales y deportes de combate, tales como: jiu-jitsu, boxeo, kickboxing, muai thay, lucha

*E-mail: jacamilo@pucsp.br 
grecorromana, kung fu, karate, capoeira, judo, entre otros (Alonso \& Nagao, 2013; Awi, 2012; Franchini \& Vecchio, 2011). La pelea se desarrolla en un espacio casi siempre rodeado de rejas, que da la sensación de jaula o cárcel, siendo su forma más conocida el denominado "Octágono".

Las raíces del MMA moderno han sido atribuidas directamente a la historia de la familia Gracie en Brasil. Ella fue la responsable del desarrollo del arte marcial japonesa denominada jujutsu, convirtiéndole en jiu-jitsu brasileño o Brazilian Jiu-Jitsu (BJJ). Los Gracie fueron también los creadores del principal evento de MMA del mundo, el Ultimate Fighting Championship (UFC). Para Awi (2012), que realizó un estudio a partir de relatos de las personas que formaron parte de esta historia, todo comenzó en 1917 cuando Gastón Gracie, siempre atento a las oportunidades de negocio, conoció en Belém do Pará a Mitsuyo Maeda (o Conde Koma, su nombre artístico), que hacía demostraciones de jiu-jitsu en plazas, teatros y pequeños circos, utilizando casi siempre hombres mucho más grandes que él como adversarios. En este momento Gastón vio una oportunidad de asociarse a Maeda, con la idea de desarrollar un circo que pudiera transitar el Amazonas con exhibiciones de jiu-jitsu y, a su vez, domesticar la agresividad de su primogénito Carlos, que en esa época tenía 15 años.

Carlos se convirtió posteriormente en el profesor de los hermanos más jóvenes de la familia, Oswaldo, Gastón Filho, George y Helio. Fueron tres años de clases y exhibiciones artísticas con una dedicación extrema de Carlos. Este habría entendido que el jiu-jitsu sería la única lucha en que el más débil podría vencer al más fuerte, tal como Conde Koma hacía en sus presentaciones (Gracie, 2008). Más tarde fue el hermano menor, Hélio Gracie, quien perfeccionó las técnicas de defensa, utilizando estrategias para que fuera posible vencer combates con adversarios de un peso superior a 20 kilos respecto al luchador de jiu-jitsu.

Si bien la proximidad con el poder podría haber ayudado a la propagación del jiu-jitsu, lo que parece haber contribuido de modo preponderante fue la capacidad de la familia Gracie de venderlo como el arte marcial más eficiente del mundo. Para esto, las artes marciales consideradas enemigas, sobre todo las luchas en pie, fueron cruciales. La capoeira (la lucha brasileña más conocida), el boxeo (por la constante y progresiva influencia norteamericana), el kung fu, el karate y el taekwondo (por la influencia del cine, sobre todo con Bruce Lee y Jean-Claude Van Damme) la lucha libre y el muay thai (que poseían un significativo espacio en Río de Janeiro) eran los principales oponentes del jiu-jitsu. Bastaba una pequeña provocación para que los Gracie desafiaran alguna otra modalidad de lucha y probaran su supremacía.

Con el sueño de llevar el jiu-jitsu al mundo, en 1993 Rorion Gracie creó el UFC en los Estados Unidos con el apoyo de Art Davie (un ejecutivo de marketing) y su famoso alumno Jonh Milius (director de la película Conan el Bárbaro). Siguiendo la idea de los antiguos gladiadores romanos y las antiguas luchas épicas, realizaron el primer evento reuniendo a ocho luchadores de varios estilos (boxeo, karate, jiu-jitsu, etc.), que se enfrentaron en una misma noche dentro de una jaula de formato octagonal. No había categorías de peso, guantes, protector bucal, establecimiento de rounds, o límite de tiempo. A pesar de ser conocido como un torneo "sin reglas", había algunas limitaciones: no estaba permitido golpear con el dedo en el ojo del adversario y tampoco lanzar golpes a la región genital (Awi, 2012).

Royce, el competidores de menor peso y también miembro de la familia Gracie, luchó tres veces en el primer evento del UFC, proclamándose campeón sin tener siquiera "un ojo morado" (Alonso \& Nagao, 2013). Royce fue elegido porque la familia quería a alguien que pareciera una "persona normal", con el biotipo magro, y no un atleta con un físico fuerte y definido, como era el caso de su hermano Rickson. El objetivo era exaltar la lucha y no el luchador. Así, Royce fue elegido para luchar porque su victoria representaría todo lo que el Gracie Jiu-Jitsu siempre quiso divulgar, que "David podría derrotar a Goliat" (Awi, 2012).

Tras intensas presiones políticas y diversos tipos de dificultades para que el evento se pudiera realizar, el UFC entró en declive, sobre todo a partir de su cuarta edición. Así, el evento tuvo que ser reformulado, crear reglas, rounds, profesionalizar a los jueces y establecer límites de tiempo para que pudiera ser sancionado por las comisiones atléticas, buscando ganar el status de deporte y así mantenerse activo. Después de su 5ạ edición el evento terminó siendo vendido por los Gracie, 
debido a que había perdido las características preconizadas por ellos: el ideal de ser "lo más parecido posible a una pelea real" (Camilo, 2016).

A lo largo de los años sucesivos la modalidad sufrió cambios importantes para que pudiera emitirse más libremente por los medios de comunicación y ser aceptada (o tolerada) por los severos críticos del MMA. En esta línea, Sánchez y Malcolm (2010) apuntan que el MMA ha oscilado entre formas más y menos violentas, realizando pequeños cambios para mantener la atracción de los espectadores bajo reglamentos cada vez más estrictos, sólo para aumentar la sensación de violencia controlada. Con esto ha conseguido imponerse en el mercado deportivo, con un número creciente de fans, patrocinadores, practicantes, profesionales en general, eventos, artículos deportivos y espacios en los medios de comunicación (Deloitte, 2011). En esta actividad es deseable que los luchadores muestren sus habilidades en diferentes artes marciales, no sólo para ganar la lucha sino también para atraer al público y reivindicar un lugar destacado entre los otros luchadores (Wells, 2012). El camino recorrido por el MMA ha generado una compleja red formada por atletas, técnicos, profesionales de la salud, fans, suplementos o anabolizantes, entre otros. Esta modalidad es practicada en innumerables países y posee eventos en prácticamente todo el territorio brasileño (Camilo, 2016).

\section{La Teoría Actor-Red (TAR): aspectos epistemológicos y ontológicos}

La posición que se adopta en este estudio es el Construccionismo Social en interlocución con la Teoría Actor-Red (TAR). En este encuentro ontológico y epistemológico tenemos: el entendimiento de que las realidades se construyen en diferentes prácticas, la importancia de los humanos y los no humanos en esta construcción, la ruptura con las dicotomías interior-exterior, sujeto-objeto, mente-cuerpo y la ruptura entre las macroestructuras sociales y económicas (Cordeiro \& Spink, 2014; Law \& Mol, 2008). La hipótesis es que el MMA es una modalidad múltiple, esto es, que no está dotada de una unidad universal o de una característica definida a priori. En este sentido, las versiones pueden ser contradictorias, polémicas o complementarias y solo pueden ser comprendidas a posteriori de las prácticas.

Es importante señalar también la diferencia entre multiplicidad y diversidad según la teoría del Actor-Red. Cuando decimos que hay varias perspectivas de un objeto, estamos hablando de diversidad. Decimos, por ejemplo, que el MMA es un deporte desde la "visión" de alguien o de algún grupo de personas. En este caso, lo que cambiaría son solamente las miradas sobre dicho deporte. Pero en la multiplicidad decimos que el objeto solo pasa a existir a partir de las prácticas o acciones, ocurriendo en ambientes distintos con diversos actores involucrados. Cuando hablamos que es un objeto múltiple, estamos diciendo que es diferente $\mathrm{y}$, al mismo tiempo, singular. Es, en palabras de Mol (2002), más que uno, al mismo tiempo que es menos que muchos. Es como el objeto fractal de las matemáticas, algo que está entre el cero y el uno (Mol, 2002). La noción de objeto fractal defendida por Mol, prestada de las matemática, remite a un objeto fraccionado, pero que también se reúne, y tiene complejas e intrincadas relaciones. La implicación es que las realidades pueden ocasionalmente chocar, a veces colaborar, o depender una de las otras (Mol, 2002). Se tiene aquí el MMA como un objeto fractal.

Pero, ¿qué permite esa fractalidad? 0 mejor, ¿cómo manejamos el hecho de que haya varias versiones del MMA que se crean a través de diferentes prácticas? Tal vez, una de las maneras más comunes sea omitir las controversias que permean el campo, tratando el MMA como si solo tuviera una manera de existir. Esto ocurre, por ejemplo, cuando decimos que el MMA es sólo deporte, es sólo una pelea o es sólo un evento rentable. Se trata de una forma reduccionista de concebir sus complejidades. Sin embargo, es importante decir que, aun existiendo tentativas de estabilizar algunas versiones, el MMA sigue involucrado en innumerables controversias, ya sea en diferentes vehículos mediáticos o en discusiones legislativas (e.g., tramitación del "Día del MMA", en contraposición a otro proyecto de ley que intenta su prohibición en Brasil). Así, en diferentes prácticas, el MMA se traduce en versiones complejas y difusas. De este modo, nos interesó investigar aquí las versiones atribuidas al MMA que circulaban en diferentes espacios del cotidiano de sus luchadores, en dos gimnasios especializados. 
En distintas vertientes de la TAR, la cuestión ontológica es reconfigurada al destacar que la realidad en la que vivimos se hace (enacted) y se configura y se reconfigura en una multiplicidad de prácticas. Siendo producto esta realidad de prácticas sociales, diferentes maneras de hacer la realidad tienen consecuencias y efectos y poseen connotaciones políticas. Por ello Mol (1999) utiliza la expresión "ontologías políticas", aclarando la unión de estos dos términos: ontología y política. La ontología, en el lenguaje filosófico, tiene que ver con la condición de posibilidad con las que vivimos (Spink, 2015). Cuando se combina con el término política, esto sugiere que las condiciones de la vida no están predefinidas, listas y estables, sino que por el contrario son definidas por ellas. Así hay una multiplicidad de maneras de hacer (enacted) objetos coexistiendo, que suscita cuestionamientos acerca de sus elecciones (las connotaciones políticas): ¿Qué opciones existen?; ¿Que implican?; ¿Cómo se hacen las elecciones?; ¿Quiénes eligen y por qué?; ¿Quién debe estableces las opciones? En palabras de Mol (1999, p. 75), "La realidad no precede a las prácticas del mundo en que interactuamos, pero es remodelada por esas prácticas. Así, el término político permite referirse a este tipo de proceso activo de moldeado y al hecho de que su carácter sea tanto abierto como contestado".

El argumento de Mol apunta también que la realidad es histórica, cultural y materialmente localizada. Pero, ¿localizada dónde? Por ejemplo, los estudios acerca de los riesgos del MMA sobre los cuerpos de los deportistas: se entienden como una práctica social (que involucra personas, con distintas afiliaciones científicas y profesionales, así como el acceso que se tiene a los deportistas y con qué abordaje se realiza) y materialmente localizada (en laboratorios con su correspondiente equipamiento). Con ello, se parte del principio de que, si la realidad es histórica y materialmente localizada, entonces es múltiple. Pero esa multiplicidad se contrapone a otras posturas y epistemologías que se basan en la pluralidad, como el perspectivismo (la realidad se cambia dependiendo de quien mira). El perspectivismo rompió con el monopolio de la verdad única y estable, pero no se multiplicó en la realidad: sólo multiplicó los ojos de los observadores.

Para Mol (2002) la multiplicidad apunta hacia una realidad que es construida y objetivada, y no meramente observada, como sugiere el perspectivismo. Como tal, al trabajar con ontologías y sus implicaciones políticas, lo que interesa es entender las prácticas que se han identificado. El foco pasa a ser la relación que se establece entre personas en localizaciones únicas (Law \& Mol, 2008). A partir de estas consideraciones, nuestro objetivo en este trabajo es estudiar el MMA desde una perspectiva relacional, marcada por las múltiples versiones que se activan en su práctica, que son igualmente relacionales. Como una posibilidad múltiple, también, de que estas versiones del MMA, con las cuales convivimos, se posicionen y sean posicionadas, como fruto de nuestras andanzas por el mundo (dentro y fuera del mundo del MMA).

\section{Sobre la construcción de la pesquisa: objetivos y método}

La presente investigación formó parte de una investigación de doctorado de la primera autora de este artículo (Juliana) y tuvo la tutoría de la segunda autora (Mary Jane). Las autoras se reunían mensualmente para discutir el progreso de la investigación, creando estrategias de acercamiento a los actores, así como seleccionando las visitas que se harían en los siguientes meses. Además, estos encuentros pretendían reflexionar sobre las prácticas y las diferentes acciones que ya habían sido vivenciadas por la primera autora.

Hemos seguido la etnografía empleada por Latour (2000) y Mol (2002, 2008), teniendo también proximidad con los estudios de Wacquant (2002) y Spencer (2012, 2013a, 2013b). En este ámbito, solo es posible hablar sobre la multiplicidad del MMA al hablar de las prácticas que se han vivido. Por este motivo, una de las autoras de ese artículo, Juliana, pasó un año conviviendo e interactuando con diversos actores involucrados en innumerables prácticas, de enero hasta diciembre de 2014. Sin embargo, es importante decir que la decisión de convivir durante un año trabajo de debió también al ciclo de eventos de MMA que ocurren en ese intervalo temporal (a modo de "temporada"). ¿Qué es el MMA? Esta fue la pregunta principal que guío el estudio.

Tenemos aquí una ontología de la práctica ubicada en la propia práctica, configurando, por lo tanto, el que Mol (2002), llamó praxiografía. La praxiografía sería una metodología narrativa que 
considera la amplitud de los agentes, instrumentos, instituciones, ambientes y sus entornos, para el mejor entendimiento del fenómeno que se quiere describir y comprender.

Para ello se adoptaron varias estrategias metodológicas durante la permanencia en los gimnasios investigados, que se articulan mediante la etnografía, la observación participante y las conversaciones (espontáneas o intencionalmente estimuladas). En ese recorrido metodológico se siguió a los actores en las prácticas que nos fueron autorizadas a conocer (Latour, 2012). Utilizamos un diario de campo para registrar y ordenar todo el material producido durante la investigación. Los relatos textuales son el laboratorio del científico social, estando menos obligado al deber de ser exacto y más a la inflexión histórica de lo que se pretende narrar. En vez de trascribir en el diario "palabras fieles", la descripción profunda pretende hacer de cada punto del texto una encrucijada y reflexión (Latour, 2012). Los relatos textuales que serán tratados aquí no se filtran con interpretaciones ya que la idea es que la descripción habla por sí sola y que, si necesita ser explicada, no será una buena descripción (Latour, 2012).

En el siguiente apartado presentamos las conversaciones, observaciones y las distintas prácticas que presenciamos o en las que participamos en este trabajo de campo.

\section{Deporte, espectáculo y la lógica mercantilista: la multiplicidad del Mixed Martial Arts}

Comenzamos presentando un fragmento del diálogo de una interacción de la investigadora (Juliana), con un luchador (Jaul) y su esposa (Fabiana), en un Gimnasio de MMA, que será llamado aquí "Gimnasio A". Excepto el nombre de la investigadora, todos los otros que serán aquí presentados son ficticios.

Luchador Jaul: Voy a luchar en un evento en la costa. Este necesito ganarlo. Estoy entrenando bien, estoy fuerte, sano, sin lesión. Voy a ganar.

Esposa del luchador Jaul - Fabiana: Ah, este evento está muy bien organizado, ¿sabes? Tiene reglas, pagan bien.

Luchador Jaul: Y ellos hacen un espectáculo por allá. He luchado otras veces y me ha gustado mucho el clima.

Investigadora Juliana: ¿Y cómo es el apoyo médico por allá? ¿Si alguien se lesiona, por ejemplo, cómo actúan?

Luchador y su esposa se ríen

Esposa del luchador Jaul - Fabiana: Ah, Dra... No hay. Si tú se lesionas, ellos como máximo, te llevan a una enfermería. Es una atención muy básica, una sutura aquí, una analítica de sangre allí y sólo. Pero Jaul está bien, nunca ha estado tan fuerte. ¡No hay riesgo!

Luchador Jaul: ¡No quiero tampoco pensar en eso! No me voy a lesionar, necesito luchar una vez al mes, tengo que pagar las cuentas.

(Él ganaría el equivalente a €70,00 por luchar en ese evento)

Diario de Campo, marzo de 2014.

Este diálogo demuestra, al menos, tres lógicas que se reprodujeron en diferentes conversaciones y prácticas en los gimnasios donde recolectamos las informaciones. La primera, comienza con lo que dice el luchador Jaul, que habla acerca de la legalidad, reglas y racionalidad a las que se vincula el deporte del MMA. El cuerpo fuerte, preparado para el combate, reduce los riesgos y la probabilidad de sufrir lesiones, como apunta también su esposa. Además, las lesiones y la experiencia con el dolor afectan el ideal de masculinidad hegemónica, ya que estos atletas se apoyan en este ideal para hacer frente al miedo, al dolor y a las equivocaciones dentro de la jaula. Esta es la visión del MMA como deporte. El show del MMA también está allí. Las risas de Jaul y Fabiana señalaban que la preocupación por los detalles para incrementar la emoción del público no era proporcional al cuidado que se tenía con los luchadores, este es el MMA como espectáculo. La tercera lógica es que en el MMA hay que luchar para vivir, para pagar cuentas, aunque sea para ganar €70,00. ¿Cómo costear el sueño de convertirse en un luchador destacado? Aquí está presente el MMA mercantilista. 


\subsection{El MMA como deporte}

Un hombre buscando MMA para su hijo de siete años en el Gimnasio A: ¿Aquí tiene MMA infantil? Quiero que mi hijo sea una cáscara gruesa. Si no se convierte en atleta, al menos no llevará una pelea a casa.

Recepcionista Fabiana: Hum... MMA no, pero tenemos Jiu-Jitsu Kids. ¡Es muy bueno para los niños!

Diario de Campo abril de 2014

El MMA como deporte es el reducto predominante de la educación física y de los diferentes profesionales de la salud: médicos, nutricionistas, psicólogos, fisioterapeutas. Los argumentos de Fabiana para el posible cliente tenían este sentido: "ser una puerta de camino al deporte", "aprender a seguir reglas" y "conocer su cuerpo". En esta lógica, un luchador profesional pasará a ser un "atleta" y a contar, siempre que sea posible, con un equipo de apoyo para aumentar su rendimiento. Una victoria pasa, entonces, a ser la victoria de un colectivo de profesionales y no sólo del "cáscara gruesa" que se arriesga en un combate.

En lo que se refiere a los entrenamientos de modo general, se puede decir que, en las academias estudiadas había entrenamientos específicos, cuidadosamente planificados y registrados. También había algunos cerrados al público, "secretos" en el discurso del técnico, destinados al trabajo de determinados movimientos, y muchos incentivos verbales. El adversario era estudiado principalmente por el entrenador principal (Head Coach). Así, los "contragolpes" eran exhaustivamente entrenados y visualizados en la expectativa de que el atleta obtuviera éxito en la lucha. Teléfonos móviles, ordenadores y tablets, todos estos dispositivos estaban constantemente presentes para auxiliar el entrenamiento.

Investigadora Juliana: Me enteré de que usted luchará. ¿Está feliz?

Luchador Fernando: ¿Por qué no? ¡No veo la hora! Necesito ganar ese combate, mi familia y amigos vendrán para verme.

Investigadora Juliana: ¿Ya sabes quién es tu adversario?

Luchador Fernando: Sí, él no es brasileño. Va a ser un combate difícil porque él tiene mucha experiencia. Pero yo he memorizado todos sus movimientos. Tengo aquí en mi móvil su última lucha. ¿Quieres verla? ¡Ah, puedo enviártela por Whatsapp!

Gimnasio B. Diario de Campo mayo de 2014.

Los vídeos del adversario eran memorizados, aunque fueran luchas antiguas. El equipo de apoyo al atleta también asistía aportando la perspectiva la especialidad de cada uno de sus miembros. Más que un accesorio o complemento para la preparación, los vídeos eran piezas fundamentales. Esta misma realidad fue discutida y presentada en la etnografía hecha por Vaittinen (2014), en dos gimnasios de MMA, en el norte de Inglaterra.

El MMA brasileño carece de un calendario deportivo predeterminado y normalmente no se tiene conocimiento previo del adversario, ya que la invitación a la lucha, a veces, llega pocos días antes del evento. Las ligas que se exhiben en televisión dependen de la divulgación del calendario del UFC (el principal evento de MMA mundial) para conseguir "encajar" sus eventos. Otras ligas nacionales, que no se exhiben en la televisión, esperan las aportaciones de patrocinadores para que puedan organizar un evento. Por esta razón muchos atletas son invitados para luchar con poco tiempo para prepararse, lo que los expone a sufrir lesiones y a las temidas derrotas. Otro factor que determina que la invitación no se realice con antelación es que una lucha programada es frecuentemente cancelada, o porque alguno de los atletas se lesiona, o porque recibe una invitación con mejores condiciones económicas en otras ligas. Esta realidad está presente en todas las ligas de MMA y coloca a atletas y técnicos en la difícil situación de decidir aceptar o no la invitación para el combate.

A diferencia de otros deportes de combate, en el MMA la participación del atleta en la competición depende de una invitación. Aquí cabe destacar que, para quien está empezando su carrera de luchador, o para los que no tienen un currículum atractivo para el empresario de una liga de MMA (número de victorias), aceptar apresuradamente un combate puede ser una de las únicas 
alternativas para competir. Esta realidad nos ayuda a entender la felicidad del luchador Fernando, al tener su lucha programada.

“Quién será mi adversario?” Esta es una duda y una angustia que ronda sobre los atletas. ¿Cómo prepararse para un combate sin saber quién es el adversario, sus puntos fuertes y sus limitaciones? Esa incertidumbre normalmente se enfrentaba con la creencia de que se está siempre preparado, de que se puede ganar de cualquier luchador en cualquier circunstancia y de que un "cáscara gruesa" no debe tener "sensiblería"; un "cáscara gruesa" siempre acepta la lucha. Para Le Breton, (2009) tendríamos aquí una relación de género, donde el orgullo de los hombres al demostrar su libertad, el enfrentamiento al miedo y al dolor, así como al considerar la petición de cautela de los profesores como algo secundario, serían conductas de riesgo valoradas mediante un significativo llamamiento a la virilidad.

En ese sentido Hirose y Pih (2009), apuntan que, aunque existen variaciones culturales importantes, el MMA tiene dos rasgos marcados que apelan a la masculinidad de los practicantes: aquellos que adoptan el estilo de golpear, abofetear y patear a un adversario (por ejemplo, los que se utilizan en las técnicas de lucha agarrada y sumisión, que puede dar la impresión de ser "menos violento"). Los autores apuntan que, en la cultura del MMA, las técnicas de striking (golpeo) son vistas como más violentas y, por lo tanto, más viriles que las técnicas de grappling (lucha agarrada), En ese sentido, un luchador que es derrotado por ser noqueado mantiene su masculinidad intacta, si se compara con un luchador que se da por vencido por una sumisión ante una técnica de grappling. Esta retirada se solicita por el luchador mediante "dos golpecitos", normalmente realizados cuando el luchador está a punto de sufrir un desmayo inminente o al tener una articulación luxada o casi luxada por el adversario. Por esta razón, muchos se niegan a dar los "dos golpecitos", sufriendo lesiones importantes o llegando a perder la conciencia.

Las heridas y las cicatrices se convierten en marcas de masculinidad, convirtiéndose en símbolos de prestigio. Demuestran cuánto se consiguió soportar y cuánto se fue de "duro" en un determinado combate. Congruente con esta discusión, pero hablando en el ámbito de hinchas de fútbol, Zucal (2005) apunta que los que luchan y demuestran resistencia al dolor se convierten en poseedores del simbólico "aguante". Son los que "aguantan" que pasan a ser considerados "verdaderos hombres".

La exacerbación de los aspectos viriles, hostiles y violentos fue también encontrada por Nascimento et al. (2011, p. 205) al investigar cómo los luchadores de artes marciales, entre 1996 y 2009, han sido reflajados en dos revistas especializadas de gran circulación en Brasil, Gracie y Tatame. Para los autores, las revistas reiteraron imágenes tradicionales del hombre, "que, por su carácter prescriptivo, daban a entender, de forma explícita, que ser mejor luchador es también ser mejor hombre". Pero también existen reglas del deporte. La violencia que muchos reclaman estar presente en el MMA está regulada y controlada, con reglas específicas que son sancionadas por la colectividad del MMA. Han existido modificaciones en el trascurso del tiempo, las cuales partieron desde las peleas o combates programados en las calles a un sistema administrado por empresas, donde hay deberes y derechos, privilegios y responsabilidades.

Congruente con el estudio de Matthews (2016), que habla acerca del boxeo, a pesar de la creciente inclusión de las mujeres en el deporte, los espacios donde se transitan las luchas siguen fuertemente arraigados y producidos por las persistentes narrativas patriarcales. Estas narrativas hablan sobre los papeles destinados a los hombres y sus masculinidades, manteniendo la conexión discursiva con la promesa de dominación y estabilidad. Así, las narrativas que conectan a los hombres con la violencia, la agresión y el poder físico apoyan los comportamientos simbólicamente vinculados a la virilidad. Aguantar todo el que la organización deportiva le pide, nunca decir "no" a los entrenadores, intentar ganar una lucha de cualquier manera (hasta que su vida esté en riesgo), marcar (con los tatuajes) y dejar marcado los cuerpos (con cicatrices), son algunas de las manifestaciones de la masculinidad hegemónica.

En el MMA como deporte, una de las formas de mantener la igualdad formal entre los luchadores es garantizar que estén en un mismo nivel de peso. Sin embargo, a menudo los atletas se inscriben en categorías de peso inferiores a su peso "real", lo que hace que tengan que perder muchos kilos poco antes de la lucha. Por esto utilizan la deshidratación como una manera peligrosa, 
pero necesaria para competir mejor (intentar sacar los líquidos del cuerpo, a veces el equivalente a 15 kilos). Pero ¿cómo mantener la fuerza, la resistencia y la concentración, teniendo que someterse a un proceso desgastante y doloroso para perder los líquidos del cuerpo poco antes de una lucha? Por esta razón, el "pesaje" que ocurre un día antes del combate es un hito para el atleta. El luchador sube en la balanza, miden su peso y, si está con el peso correcto, es aprobado para la lucha. Si no alcanza el peso, tendrá dos horas para intentar deshidratar aún más y "sacar el peso". Si no es capaz, tendrá penalizaciones: (1) puede perder inmediatamente la lucha si el oponente se niega a luchar; (2) puede perder un porcentaje de la remuneración que fue acordada entre él y el gestor del evento; (3) empezar la lucha con un punto menos. A pesar de haber surgido como una modalidad de lucha donde "Vale-Todo", el MMA trajo el deporte al combate, y con él reglas y prohibiciones.

\subsection{El MMA como espectáculo}

En el MMA como espectáculo, el practicante es posicionado como luchador, guerrero, gladiador, combatiente y artista marcial, diferente del MMA como deporte, en el que es presentado como atleta. Hay muchos luchadores que son valorados por el espectáculo que proporcionan al público y, con esto, generan una significativa rentabilidad para los eventos de MMA: Conor McGregor, Anderson Silva, Jon Jones, Ronda Rousey, Georges St. Pierre, son algunos de ellos. Esta versión de MMA también fue registrada por Spencer (2013b).

El espectáculo prima sobre la salud y se opone a las reglas que forman parte del deporte. La salud se deja en segundo plano, pues lo que está en juego es la fantasía que el espectáculo proporciona por medio de sus luchadores. Esta forma de transformar la lucha en un espectáculo ocurre de modo estudiado y calculado, contando con la ayuda de profesionales de marketing, periodistas, promotores de eventos, productores artísticos, narradores especializados, editores de videos, fotógrafos, profesionales especializados en audiovisual y merchandising.

Acerca de esto Downey (2014) argumenta que el MMA está envuelto actualmente en una importante paradoja. Por una parte, hay opositores que hablan que la modalidad es una degeneración generalizada de costumbres sociales, que es peligroso y violento, y así no se puede ver como un deporte. Por otro lado, los aficionados creen que la modalidad es demasiada aburrida y sin emoción después de la implementación de las reglas que acabaron con la lógica del "There Are No Rules!" (¡No hay reglas!). Se puede entender que esta paradoja es una de las confrontaciones principales entre el "MMA como deporte" y el "MMA como espectáculo".

Los medios de comunicación son fundamentales para la divulgación del MMA como espectáculo, y también participan de esta paradoja. En una dimensión negativa, que no lo considera como un deporte, la modalidad es un supuesto espectáculo de pelea humana, espectáculo de sangre, el espectáculo de la violencia, el circo de lucha. De manera inversa, pueden considerarlo un gran espectáculo, un show de luchas, guerreros en acción y el clásico “There Are No Rules!” Así, un evento de MMA se destaca como un espectáculo, tanto para quien lo valora directamente como para los críticos de la modalidad (que igualmente estereotipan su práctica en su forma actual).

La versión del MMA como espectáculo tal vez sea la más explotada por los medios de comunicación y la que ha ayudado al crecimiento de la modalidad por el mundo, ganando críticos, fans o patrocinadores, entre otros. Cada detalle es pensado y estudiado con el objetivo de aumentar el entusiasmo, desde la divulgación del evento hasta las entrevistas finales con los ganadores del combate. No son raras las ocasiones en que los animadores son incentivados a hacer que los atletas se peleen (en oposición al deporte) para hacer el evento más atractivo.

El espectáculo comienza con la divulgación del evento por medio de carteles confeccionados con colores oscuros como el negro, gris, rojo, naranja y azul oscuro. Las palabras utilizadas en la publicidad convocan a un evento que será intenso y único. Pero la divulgación puede partir del propio octágono, donde un luchador convoca a otro para un futuro combate. Puede gritar, despreciar, desafiar. Empresarios y promotores ayudan en esos momentos, mostrando proximidad con el MMA mercantilista. Cuando el público reaccione positivamente, o cuando se demanda en las redes sociales, es posible que la pelea se organice. En las fotos que divulgan un evento, los luchadores están normalmente con los puños cerrados, y el semblante agresivo, hostil y combativo. 
Tatuajes, ropas personalizadas y otros accesorios apoyan los diferentes escenarios y marcan las afiliaciones religiosas de los luchadores, sus vínculos con alguna arte marcial, gimnasio o hasta con algún patrocinador. También es común el uso de la nacionalidad de un luchador para intensificar la rivalidad.

Luchador Marcelo Loco: Antes de luchar con el tipo, le tengo odio. Quiero matarlo. ¡El público espera eso de mí y eso es lo que voy a dar... Show! Por eso me consideran loco. Me gusta ser así. Ir allá y ganar no tiene gracia. Yo quiero show, quiero ser diferente, doy un golpe que nadie espera. Ese soy yo.

Gimnasio A - Diario de Campo, abril de 2014.

Se resaltan especialmente las cicatrices, sobre todo aquellas adquiridas durante la práctica del MMA. En este sentido, los hematomas auriculares ganan especial atención. La mayoría de los hematomas auriculares proceden de los entrenamientos y de las luchas en el suelo, como el jiu-jitsu y el judo, en virtud de la intensa fricción de la cabeza del luchador con el tatami.

Luchador Ricardo: Una oreja de "coliflor" es siempre una oreja de "coliflor". Yo soy joven, no quería tenerla, pero como soy un experto en jiu-jitsu no tengo otra opción. Además de esto, sé que a la gente le gusta verla. Cuando tengo que luchar miro mi oreja y recuerdo todo lo que pasé para llegar hasta la lucha. Me motivada, me hace sentir fuerte y así yo sé que puedo vencer mi oponente.

Gimnasio A. Diário de Campo março de 2014.

Otro factor que expresa las revelaciones de un evento de MMA son los mensajes agresivos dirigidos al adversario, enviados por las redes sociales, en entrevistas colectivas con los medios de comunicación o en viajes para la divulgación de la lucha. La "pelea", el conflicto, el duelo, las amenazas y hasta las ofensas componen este cuadro de divulgación del evento. Una lucha sin ese ingrediente es considerada por muchos como sin interés y puede no atraer ni al público ni a los patrocinadores. Las ofensas en las redes sociales, las miradas duras dirigidas al adversario, reclutan a otros actores para la acción.

El ritual del pesaje es tan importante como el día del combate. En él los luchadores necesitan cumplir una tarea que se concibe tan ardua como propia la lucha en sí: alcanzar el peso exigido. Privaciones físicas, dolores y lesiones en el cuerpo, además de la ansiedad por el combate futuro, son elementos que están en este momento. Durante el pesaje se tiene un presentador o locutor que es responsable de llamar a los luchadores para la balanza, además del propietario de la liga de MMA y de las mujeres que serán las ring girls. El público muestra su presencia, sobre todo los aficionados.

Luchador Fernando: Por más que esté exhausto, me gusta llegar hermoso para el día del pesaje. Por eso siempre hago un peinado y una coloración diferente en mi cabello.

Gimnasio B. Diario de Campo junio de 2014.

Los luchadores son llamados uno a la balanza, en la misma secuencia en que será el combate. Van al escenario con sus entrenadores, se quitan la ropa y se quedan en traje de baño. Hay aquí una parte importante del espectáculo, ya que las ropas retiradas, el traje de baño y otros accesorios llevados al escenario por los luchadores, a veces ya tienen un sentido de pelea y agresividad para la lucha. El presentador llama a un luchador, que se quita la ropa, sube en la balanza y si alcanza el peso hace poses. Cuando los luchadores no alcanzan el peso en traje de baño, también podrían quitárselo. En este caso, los ayudantes cubren sus partes íntimas con toallas para las cámaras. Las mujeres presentes se desplazan hacia los laterales del escenario para no tener acceso a la desnudez del luchador, lo que es comentado por la audiencia con malicia. Luego el luchador aguarda el mismo proceso de su oponente y cuando terminan practican las poses para las fotos y la llamada "encarada".

El día del evento es un espectáculo de luces, colores y movimientos. El público parece vestirse de manera personalizada. Muchos hombres y mujeres usan camisetas que remiten a algún arte marcial o gimnasio de combate. Llegan extasiados 
Hinchada (antes de un combate cuando un luchador flaco entra en la jaula): uuuu, ¡va a morir! Uuuu, ¡va a morir!

En un evento del UFC en Brasil. Diario de Campo, diciembre de 2014.

Los luchadores, como personajes principales, aguardan con su equipo técnico la entrada entre bastidores. Cuando son llamados entran al sonido de una canción elegida por ellos mismos. Rap, música religiosa, rock, músicas brasileñas, himnos de un país, se utilizan con frecuencia. La platea vibra. Las ring girls circulan con el cartel apuntando el round que será disputado y reciben comentarios "masculinos". Mientras eso sucede las bebidas alcohólicas circulan entre el público del evento (en algunos eventos están prohibidas), se exhiben los vasos para las cámaras.

La lucha es casi siempre imprevisible, lo que aumenta la adrenalina de todos los implicados. Alguien puede lesionarse seriamente, puede sangrar mucho, pueden suceder situaciones "divertidas" (como algunas escenificaciones intencionales de los luchadores), puede terminar rápido o ir hasta el final. Depende. No se puede predecir. Es inusitado. Pero los luchadores no actúan solos. La platea grita, abuchea (sobre todo cuando se creen que la lucha es poco combativa), parece sentir los dolores o el éxtasis de la victoria. ¡Esa victoria es para ustedes! Dijo el luchador Marcelo del Gimnasio B, en diciembre de 2014, haciendo que lágrimas rodaran del equipo que lo acompañó.

Terminado el combate, uno de los luchadores tiene sus brazos levantados y su nombre se anuncia como ganador. A veces concede una breve entrevista y agradece a todos los involucrados, a veces inclusive a su adversario con el cual muchas veces intercambió ofensas antes de la lucha. La agresividad parece desaparecer como un hechizo, dando espacio para una relación cordial entre luchadores y equipos. Agradecimientos, abrazos y besos son frecuentes en este momento. La platea aplaude y se tranquiliza. Lista para recibir otra pelea.

En eventos con exposición en los medios, sobre todo la TV, finalizadas todas las luchas del día los luchadores dan testimonios de cómo fue todo el proceso de entrenamiento hasta el combate final. Para este ritual se llaman aquellos que destacaron en el evento, como los que ganaron algún premio extra (e.g., knockout de la noche, lucha más rápida) o los que son considerados como luchadores principales. El tono de la entrevista es tranquilo y apaciguador. Es común también que los combatientes convoquen nuevas luchas y desafíen a otros adversarios, dando inicio a un nuevo ciclo de "MMA como espectáculo".

\subsection{El MMA mercantilista}

Existe aquí la comercialización de diversos productos, la venta de productos como camisetas, gorras, muñecos de los luchadores o de servicios como la venta de entradas para los combates, pay-per-view de los combates en TV, productos todos ellos que remiten al "esté cerca de su ídolo".

Pero ese MMA no se agota aquí. Es un lugar de lucha y permanente tensión. Patrocinadores, atletas, gimnasios, productos para aumentar el rendimiento y diferentes especialistas entran en acción siempre que esto sea comercialmente atractivo. En algunas ocasiones es importante transmitir la idea de juego limpio para conquistar nuevos aliados (e inversores) y, por otro lado, es probable que alguna agencia especializada en marketing se esfuerce por vender el mismo combate de un modo distinto (esta vez como el juego "más agresivo de todos los tiempos").

En ese MMA los luchadores son trabajadores. Venden su trabajo, incluso a espaldas de la seguridad social: sin contrato de trabajo y sin el debido registro profesional, sin regulación o reconocimiento de la profesión, sin un seguro de vida, sin una asistencia médica especializada, sin una remuneración mínima y, obviamente, sin posibilidad de jubilación. Tampoco se consideran otros beneficios sociales: adicional nocturno, vacaciones, jornada máxima de trabajo, viáticos, dinero para alimentación. ¿Cómo sería entonces pensar en un accidente de trabajo? Hay una invisibilidad del trabajo: para la legislación, para los dueños de los eventos de MMA y a veces para los propios luchadores. Por esta razón, como se presentó aquí, el luchador Jaul estaba contento con recibir un pago de €70,00. 
Pocos atletas tenían algún patrocinio que les suministrase algún dinero extra. A veces, este se limitaba al suplemento alimenticio mensual. Muchos estaban casados y tenían hijos, además del sueño de convertirse en "rico y famoso". ¿Cómo costear el sueño de convertirse en profesional? ¿Cómo vivir del ejercicio del MMA? Estas eran cuestiones recurrentes y que alcanzaban a diferentes actores: luchadores, sus compañeras, sus familiares, técnicos, profesionales de salud. En contraste con esta realidad, el MMA ha ido, con el paso de los años, ganando espacio en los medios, ampliando eventos y rentabilidad. Por lo tanto, ganar una lucha es imprescindible y de esta forma las sustancias ilegales están siempre muy presentes, como una manera para ayudar a obtener la victoria, lo que no siempre tiene la aprobación irrestricta de los luchadores:

Luchador Miguel (que estaba iniciando su profesionalización): No quiero tomar (hablaba del anabolizante). Sé que es una lucha importante y no puedo perder, pero no quiero tomar. ¿Sabes, puedo confesar una cosa? Yo muero de miedo a ponerme una inyección ... Pero el maestro me dijo que, si no lo tomo, no tengo oportunidad ... Yo sé, soy delgado, no tengo musculatura, pero ¿Será que va a adelantar algo tomar si yo no logro alimentarme bien? Porque yo entreno 8 horas todos los días y no me alimento bien, no tengo dinero para comer correctamente. No sé qué hacer.... No lo quiero tomar, pero no puedo perder.

Diario de Campo, janeiro de 2014.

De este modo, el MMA mercantilista se superpone al MMA deportivo ya que no se discuten las reglas, el cuidado del cuerpo y la salud. Lo que importa es ganar la pelea, dinero y más oportunidades en el futuro. Otro aspecto presente en el discurso del luchador evidencia la cruel realidad vivenciada por él. Sin alimentación básica necesaria, entrenando ocho horas diarias y teniendo en la victoria a corto plazo la única posibilidad de continuar en su carrera. Esta misma lógica del MMA mercantilista parece que también ha estado presente en el reciente caso que involucró la penalización al famoso luchador del UFC, Jon Jones, por su reincidencia en el consumo de sustancias ilegales. La percepción compartida por muchos es que su castigo fue más blando debido a la rentabilidad que genera para la organización. Esta penalización fue criticada por muchos, sobre todo a los defensores del MMA como deporte.

La falta de formalidad laboral también ocurre con los profesionales de diferentes departamentos que apoyan a los atletas en su preparación (entrenadores, preparadores físicos, profesionales de la salud). Durante la investigación realizada no conocimos a ningún profesional que fuese contratado formalmente. En ese sentido, la actuación de los psicólogos involucrados en el MMA se articulan con el MMA en el contexto de la economía:

Gimnasio B, noviembre de 2014. Descripción de la rutina de entrenamiento.

Juliana: Como ya estaba habituada, entro en el tatami para asistir al entrenamiento de MMA que sería conducido por el profesor Antonio. Poder ver el entrenamiento en este espacio fue una conquista que ocurrió tras una invitación formal del profesor responsable, en agosto del mismo año. Así, en un entrenamiento conducido en noviembre de 2014, observo la llegada de dos visitantes al gimnasio B, que iban a acompañar a un luchador también visitante, en su entrenamiento. Mientras ya estaba sentada en un rincón del tatami, veo que el luchador visitante pide permiso al profesor Antonio para entrar. En este momento, veo que los otros dos visitantes mostraban cierta incomodidad con mi presencia en el tatami, tal vez por no ser visiblemente una atleta, tal vez por ser la única mujer allí, tal vez porque un luchador comentó momentos antes que yo era "la doctora" del equipo.

Después de 40 minutos del inicio del entrenamiento, y sin obtener la invitación del profesor, los hombres entran en el tatami y se sientan a mi lado. Me mantengo observando las prácticas y registrando mis observaciones en mi diario de campo y veo la visible incomodidad en uno de los visitantes, hasta que el comienza a hablar:

Rodrigo (psicólogo): ¿Quién es usted? (Me preguntó con cierta rispidez)

Investigadora Juliana: ¿Soy Juliana y usted?

Rodrigo: Yo soy el psicólogo del atleta X (el deportista estaba haciendo un intercambio en el gimnasio B)

Juliana: ¡Muy bueno!

Rodrigo: Usted debe ser la psicóloga del equipo, ¿verdad? 
Juliana: A ellos (los deportistas) les gustan hablar que soy la psicóloga, pero en realidad yo soy doctoranda en Psicología Social y estoy aquí para aprender con ellos.

Rodrigo: ¿Ah sí? ¿Hace cuánto tiempo conoces el MMA?

Juliana: Comencé a estudiar el MMA en mi doctorado.

Rodrigo: Me molesto con esto. Existen muchos "curiosos" que se creen saber /conocer lo necesario para actuar en el MMA. ¿Usted sabe qué es el dolor? ¿Qué es luchar? ¿Has luchado alguna vez?

Juliana: No. Sólo acompañé a mi marido que fue campeón panamericano de Karate en innumerables competiciones y en sus lesiones.

Finalizado el entrenamiento, el psicólogo y el otro visitante buscaron al entrenador Antonio para vender sus servicios. Momentos después Antonio me llama, hablando de su incomodidad con los visitantes y el intento de sacarme de mi lugar.

Profesor Antonio: ¡Aquí no! Estos chicos quieren convertir a los atletas en monstruos. ¡Ellos son seres humanos! ¿Es difícil entender esto? Estamos comprometidos con usted, aquí nadie más entra.

Gimnasio B. Diario de Campo noviembre de 2014.

El intercambio de conocimientos entre psicólogos es reemplazado por la competición, aunque la investigadora no estaba ocupando esa función. Es válido decir que durante este entrenamiento estaba presente el luchador principal de la academia, que también era luchador del Ultimate Fighting Championship (UFC). El acoso a él no se resumía en los fans, sino también en los diferentes profesionales que intentaban ofrecer sus servicios, muchas veces sin reclamar sueldo alguno.

El UFC es actualmente la mayor liga de MMA mundial y tiene un volumen de negocios que impresiona. Los números UFC Río, en su edición número 134, que tuvo lugar el 27 de agosto de 2011, ayudaron a impulsar el deporte en el país. Se registraron 20.000 personas que participaron presencialmente del evento, 30 millones de televisores conectados en Brasil, 135 países conectados y un impacto económico de 50 millones de dólares para la ciudad de Río de Janeiro. La edición 198 del UFC, realizado en mayo de 2016, en Curitiba, fue igualmente impactante desde la lógica mercantilista. Cerca de 15.000 personas asistieron al evento previo un día antes de las luchas, que se compone básicamente del pesaje de los luchadores, siendo considerado el mayor público asistente a un pesaje ya realizado en la historia de la organización. El impacto económico del UFC en la ciudad fue de aproximadamente R $\$ 45$ millones (Agência de Notícias da Prefeitura de Curitiba, 2016). El UFC también está en la revista Forbes, que evalúa las marcas deportivas más valiosas en el mundo. De acuerdo con este ranking, en 2014, la empresa valía US \$ 1.65 mil millones de dólares y, su marca, US \$ 440 millones (Ozanian, 2014). Sin embargo, ya en julio de 2016, el UFC fue vendido por U\$ 4 billones, para el grupo chino William Morris Endeavor (IMG). El acuerdo es posiblemente la mayor venta de una franquicia deportiva (Merced, 2016). En la TV de pago de Brasil, el MMA es, además del fútbol, el único deporte con un canal específico: el Combate.

El estímulo a la competición excesiva entre luchadores y gimnasios ha llevado a la quiebra de los lazos de compañerismo y ha perjudicado la cooperación entre los actores sociales que transitan este espacio, aumentando los riesgos de lesiones físicas y al estrechamiento de los lazos sociales. Como ocurre con otras categorías profesionales, la maximización del desempeño y el temor a la falta de oportunidades de luchar (equivalente al desempleo), generan también la sumisión a condiciones de trabajo degradantes.

Tal como un trabajador asalariado, un luchador de MMA, tiene su subjetividad gestionada y controlada por la organización en que actúa. Las prácticas de control y regulación se introducen a fin de maximizar el rendimiento, en las prácticas que involucran desde la educación física hasta la psicología del deporte. En ese sentido, queda poco espacio para el miedo, para la derrota, para el rechazo de una lucha cuando se está lesionado. Se agrega a esto otra variable: la crisis económica y el aumento del desempleo en Brasil. De acuerdo con la Encuesta Nacional por Muestra de Domicilios (PNAD), en 2016 se tuvo un incremento de 3,269 millones de desempleados en comparación con 2015, lo que corresponde al 12\% de la población activa en diciembre de 2016 
(12,342 millones de personas), suponiendo un crecimiento del 36\% de un año a otro (IBGE, 2016). Las consecuencias de esto se traducen en la reducción de los eventos de lucha, disminución de la hinchada pagadora, y menor posibilidad de conquistar condiciones mínimas de trabajo y de insertarse en otras actividades profesionales.

El fin del crecimiento del MMA trae la pérdida de la esperanza, del sueño de convertirse en una superestrella, del progreso social o de la posibilidad de lograr una cierta estabilidad en la vida. Con esto, muchos luchadores viven limitándose a las ganancias necesarias para su supervivencia. Piden patrocinios mínimos, tales como un suplemento alimenticio, un guante para la práctica de la lucha o una atención médica. En cambio, estampan la marca del patrocinador en una camiseta, sacan fotos o hacen una entrada en las redes sociales. Se reanudan aquí las cuestiones iniciales: ¿Cómo soportar el cotidiano de ser un atleta de MMA, invisible y precarizado como trabajador? ¿Cómo tolerar un trabajo que implica el uso del cuerpo al límite de la lesión, por el miedo a la derrota o por el miedo de no ser invitado a luchar? Se plantea un dilema.

\section{A modo de conclusión: el MMA múltiple, más que uno y menos que muchos}

Este trabajo ha usado viñetas y extractos de un estudio etnográfico hecho en Brasil, cuna del UFC, para ayudar a pensar qué es el Mixed Martial Arts. Tal como es postulado por la Teoría ActorRed, solo es posible intentar comprender esta cuestión por medio de las prácticas en las cuales la modalidad está involucrada. Específicamente, intentamos presentar narrativas y descripciones, con datos sobre experiencias para demostrar que el MMA es una modalidad múltiple.

Tal como señalaron los estudios de Mol (2002) y Law y Mol (2008), en otras realidades distintas del deporte, también hemos percibido aquí que el MMA es "más que uno": es un deporte, es un espectáculo, es un evento de orden económico. Pero también es "menos que muchos", pues sus versiones no están totalmente desconectadas. ¿Qué vincula, entonces, estos modos distintos del MMA? Una manera de reunir sus versiones es la propia denominación "MMA", ya que independiente de la especificidad de MMA de la que estemos hablando, todas atienden por el mismo nombre, haciendo que las diferentes versiones no se fragmenten. Sin embargo, la denominación también puede estabilizar la multiplicidad de tal manera que transforme el MMA en algo aparentemente coherente, singular y ordenado. Es como si el psicólogo Rodrigo, al hablar acerca de los "curiosos" que se involucran en la modalidad, estuviesen implicados en el mismo MMA que él (MMA mercantilista).

Hay también un proceso de distribución que apunta a las diferentes versiones de un objeto coexistiendo "pacíficamente", siempre que uno no intente ocupar el mismo lugar, en el tiempo y en el espacio, que el otro (Mol, 2002). Así, el "MMA como deporte", por ejemplo, involucrado en la educación física, ocupa lugares determinados y reductos del saber. Es valorado, como apuntaba Fabiana, por facilitar el conocimiento del universo deportivo, aprender a seguir reglas y conocer el cuerpo. Pero, a veces, el "MMA mercantilista" puede intentar (y a veces conseguir) superponerse, al "MMA como deporte", como fue el caso de Miguel.

Lo mismo ocurre con las actividades que implican a los inversores (MMA mercantilista) o aquellas que desean promover el espectáculo (MMA como espectáculo). Esta distribución puede chocar cuando el MMA como deporte entra en juego con el MMA que se somete a la economía, por ejemplo, "hacer la vista gorda" ante los casos de dopaje porque el atleta genera un buen rendimiento económico. El inversor "necesita" reducir los gastos y tal vez pague lo menos posible a los luchadores-trabajadores. El MMA necesita generar ganancias y puede articularse en otras prácticas semejantes que, por así decir, no chocan con las apuestas, con la inversión hecha por el empresario o que saque la adrenalina del show.

La distribución también se puede hacer de forma geográfica. El día de la lucha, en el espacio del combate, el espectáculo predomina. Son los gritos, la adrenalina, el ritual de entrada del luchador, hasta que la mano del vencedor esté levantada. Ya en las prácticas de entrenamiento (MMA como deporte) se tiene el reducto de la salud y sus controles. Como hemos dicho, son los entrenamientos específicos, pensados e registrados, así como los secretos de cada gimnasio. Por último, en la contratación de luchadores, en las apuestas, en la definición de los combates, se tiene 
al MMA mercantilista. Es decir, así distribuidas, las diferentes versiones pueden coexistir sin ser contradictorias, sin dar la idea de que se trata de una modalidad distinta. Sin ser totalmente un deporte fragmentado.

Para Mol (2002), otro modo de coordinación es la adición, en la que diferentes versiones se unen y forman un todo. Con ello, el MMA no se limita a la suma de las versiones aquí presentadas. Recluta actores, crea prácticas, influye en las personas, las legislaciones, despierta pasiones y acaloradas discusiones. En el día del combate es donde podemos observar la adición, es el día en que ciertos detalles del espectáculo están en evidencia, aunque no podemos olvidar la existencia y la superposición de distintas versiones de la modalidad. En la adición, las diferentes prácticas y lugares de actuación se alinean y suman de tal manera que pasan a referirse a un objeto único (Cordeiro \& Spink, 2014).

Hay varios modos de organizar las versiones que existen de MMA, así como hay distintas versiones que se crean constantemente en las prácticas cotidianas. Aquí hemos intentado discutir acerca de las versiones (espectáculo, mercantilista y deporte) y sus diferentes aspectos que hemos logrado identificar y comprender en este estudio etnográfico. Destacamos aquí la importancia de que se realicen otras investigaciones, en otros gimnasios, países y con otras personas, para contribuir a la presente discusión.

\section{Financiación}

Este trabajo ha sido financiado mediante la "Bolsa Disídio", destinada a los trabajadores de la PUCSP, y mediante el Plan de Incentivo a la Investigación - Capacitación Docente (PIPEq), proceso 385/2015.

\section{Referencias}

Agência de Notícias da Prefeitura Municipal de Curitiba (2016, 20 de mayo). UFC confirma preparo de Curitiba para eventos e gera impacto de $R \$ 45$ milhões. Recuperado de http://www.curitiba.pr.gov.br/noticias/ufc-confirma-preparo-de-curitiba-para-eventos-egera-impacto-de-r-45-milhoes $/ 39753$

Alonso, M., \& Nagao, S. (2013). Do vale tudo ao MMA: 100 anos de luta. Rio de Janeiro: Editora PVT.

Awi, F. (2012). Filho teu não foge à luta. Rio de Janeiro: Intrínseca.

Camilo, J. A. O. (2016). Afinal, quem são os lutadores de MMA (Mixed Martial Arts)? Manaus: OMP Editora.

Cordeiro, M. P., \& Spink, M. J. P. (2014). A multiplicidade da Psicologia Social Brasileira. Athenea Digital, 14(1), 289-300. doi: 10.5565/rev/athenead/v14n1.1101

Deloitte. Muito além do futebol. Estudo sobre esportes no Brasil. São Paulo (2011, septiembre). Recuperado de http://fbf.org.br/ckfinder/userfiles/pdf/Pesquisa Esportes Deloitte 2011 Apresentacao completa.pdf

Downey, G. (2014). "As Real As It Gets!" Producing hyperviolence in mixed martial arts. Journalism, Media and Cultural Studies, 5, 1-28. doi: 10.18573/j.2014.10268

Franchini, E., \& Vecchio, F. B. D. (2011). Estudos em modalidades esportivas de combate: estado da arte. Revista Brasileira de Educação Física e Esporte, 25, 67-81. doi: 10.1590/S1807$\underline{55092011000500008}$

Gracie, R. (2008). Carlos Gracie: o criador de uma dinastia. São Paulo: Editora Record.

Hirose, A., \& Pih, K. K. (2009). Men and Masculinities Who Submit: Hegemonic and Marginalized Masculinities in Mixed Martial Arts. Men and Masculinities, 13(2), 190-209. doi: $\underline{10.1177 / 1097184 X 09344417}$

Instituto Brasileiro de Geografia e Estatística - IBGE. (2016, agosto). Pesquisa Nacional por Amostra de Domicílios Contínua. Rio de Janeiro.

Latour, B. (2000). Ciência em ação. São Paulo: Unesp.

Latour, B. (2012). Reagregando o Social. Salvador - Bauru: Edufba.

Law, J., \& Mol, A. (2008). The actor-enacted: Cumbrian sheep in 2001. En C. Knappett \& L. Malafouris (Eds.), Material Agency: towards a non-anthropocentric approach (pp. 57-77). New York, NY: Springer.

Le Breton, D. (2009). Condutas de risco: dos jogos de morte ao jogo de viver. Campinas: Autores Associados. 
Matthews, C. R. (2016). The Tyranny of the Male Preserve. Gender and Society, 30(2), 312-333. doi: $10.1177 / 0891243215620557$

Merced, M. J. (2016, 11 de julio). U.F.C. Sells Itself for \$4 Billion. The New York Times, pp. B1. Recuperado de http://www.nytimes.com/2016/07/11/business/dealbook/ufc-sells-itselffor-4-billion.html? $\mathrm{r}=1$

Mol, A. (1999). Ontological politics: a word and some questions. En J. Law \& J. Hassard (Eds.), Actor network theory and after (pp. 74-89). Oxford: Blackwell.

Mol, A. (2002). The body multiple: ontology in medical practice. London: D. U. Press.

Mol, A. (2008). The logic of care. Health and the problem of Patient Choice. New York: Routledge.

Nascimento, A. R. A., Veloso, F. G. C., Almeida, A. C. C., Miranda, C. C. L. A., Fernandes, J. \& Nunes, K. C. (2011). Virilidade e competição: masculinidades em perfis de lutadores das Revistas Tatame e Gracie magazines. Memorandum, 21, 195-207.

Ozanian, Mike (2014, 7 de octubre). The Forbes Fab 40: The World's Most Valuable Sports Brands. Recuperado de http://www.forbes.com/sites/mikeozanian/2014/10/07/the-forbes-fab-40the-worlds-most-valuable-sports-brands-2014/\#d0100c016769

Sánchez, R., \& Malcolm, D. (2010). Decivilizing, civilizing or informalizing? the international development of mixed martial arts. International Review for the Sociology of Sport, 45(1), 3958. doi: $10.1177 / 1012690209352392$

Spencer, D. C. (2012). Narratives of despair and loss: pain, injury and masculinity in the sport of mixed martial arts. Qualitative Research in Sport, Exercise and Health, 4(1), 117-137. doi: $10.1080 / 2159676 X .2011 .653499$

Spencer, D. C. (2013a). "Eating clean" for a violent body: Mixed martial arts, diet and masculinities. Women's Studies International Forum, 44(1), 247-254. doi: 10.1016/i.wsif.2013.05.018

Spencer, D. C. (2013b). Ethnography Sensing violence: mixed martial arts. Ethnography, 15(2), 232254. doi: $10.1177 / 1466138112471108$

Spink, M. J. P. (2015). Clientes, cidadãos, pacientes: Refexões sobre as múltiplas lógicas de cuidado na atenção à saúde. Saúde E Sociedade, 24(supl I), 115-123. doi: 10.1590/S0104$\underline{12902015 S 01010}$

Vaittinen, A. (2014). Intersections: Ways of knowing Mixed Martial Arts and Visual Culture. Amodern 3: Sport and Visual Culture. Recuperado de http://amodern.net/article/mixedmartial-arts/\#pdf

Wacquant, L. (2002). Corpo e Alma: notas etnográficas de um aprendiz de boxe. Rio de Janeiro: Relume Dumará.

Wells, G. (2012). Mixed Martial Arts: Ultimate Fighting Combinations. Minneapolis: Lerner Publications Company.

Zucal, J. G. (2005). "Soy Macho porque me la aguanto". Etnografía de las prácticas violentas y la conformación de identidades de género masculino. En Hinchadas (pp. 39-57). Buenos Aires: Prometeo.

\section{Author's biographical data}

Juliana Aparecida de Oliveira Camilo (Brasil), es psicóloga, con Máster y Doctorado en Psicología Social en la Pontificia Universidad Católica de São Paulo (PUCSP). Es docente de la PUCSP, en el departamento de Psicología Social y de la Universidad Paulista (UNIP), en los cursos de gestión y psicología. Actuación en equipos de MMA y atención a atletas de alto rendimiento en las modalidades de karate, esgrima, natación y motocross. Es coordinadora del núcleo de Psicología del Deporte, en el grado y postgrado en la PUCSP. Ha realizado una estancia docente en la Universidad de Cádiz, España (2017). E-mail: jacamilo@pucsp.br

Mary Jane Paris Spink (Brasil), es Profesora Titular de la Pontificia Universidad Católica de São Paulo (PUCSP) e investigadora de productividad 1A en el CNPq - Brasil, docente y orientadora de los cursos de máster y doctorado del Programa de Estudios de Posgrado en Psicología Social de la PUCSP y coordinadora del Núcleo de Investigación en Prácticas Discursivas en el cotidiano: derechos, riesgos y salud, desde 1987. Tiene graduación en Psicología por la Universidad de São Paulo (1969) y doctorado en Psicología Social University of London (1982), y ha realizado una etapa post-doctoral en Ciencias Humanas en la Universidad de Cambridge, Inglaterra (1998). Ha orientado distintos trabajos en deportes, tales como MMA, fútbol y carreras de aventura. E-mail: mjspink@pucsp.br 